\title{
Impacts of Rural Households' Economic Strategy on Educational Life of Girls in Vietnam*
}

\author{
Tran Thi Thai Ha, Ngo Thi Thanh Tung \\ Vietnam Institute for Education Sciences, Ha Noi, Vietnam
}

\begin{abstract}
While gender discrimination was severe in Vietnam in the distant past, it has been significantly mitigated since independence. Girls and women have been treated on a more equal basis and have achieved much more success than what they had in the past and in relation with boys and men. An analysis of the available data will allow us to show that there has been an increase in the number of female students at the different levels of education. However, the findings from a research conducted in rural areas shows that girls still suffer from more pressure and face more challenges in education than boys, and tend to be sacrificed when the family has to make a choice. The proposed article is based on a research conducted from 2013 to 2015, in five provinces located in three main areas: the North, Centre, and South of Vietnam. Financed by the National Foundation for Science and Technology Development (NAFOSTED) and statistical data of other studies, the educational strategies of rural households were investigated through in-depth interviews and focus group discussions with parents of children enrolled in primary and secondary school.
\end{abstract}

Keywords: education, girl eduaction, rural education, rural household, impacts of economic stratery

\section{Introduction}

\section{Project Introduction}

"Current rural households' education in the context of socio-economic transformation in Vietnam" is a research topic which is implemented by Vietnam Institute of Education Sciences (VIES) under sponsorship of Naforsted Fund. The topic has been implemented from 2013 to 2015, following the main objective which is to:

1. clarify the role of households in educational strategy (approach, orientation, and plan), investment in and concern for education of rural members in the context of Vietnamese socio-economic transformation;

2. analyze the relation between the role and educational strategy of households and the socio-economic restructuring process in the rural area, and policy-based implications of this research result;

3. propose solutions (from the education system, community, mechanism, and policy) to enhance educational quality and effectiveness of rural households to meet the requirements of socio-economic transformation process in the current period.

During the research implementation period, the research team clarified adaptation of households with increasingly strong socio-economic transformation process in the rural area through analysis of households'

\footnotetext{
* Acknowledgement: This article study was conducted within the framework of the research project (No. VI2.3-2011.12) funded by the National Foundation for Science and Technology Development (NAFOSTED).

Tran Thi Thai Ha, Ph.D., associate professor, Vietnam Institute of Education Sciences.

Ngo Thi Thanh Tung, M.A., senior researcher, Vietnam Institute of Education Sciences.
} 
economic strategy. The research team also analyzed influence and impacts of households' economic strategy on educational life of girls. This research result is one of important results of the research topic.

\section{Research Methods}

This research is implemented by both quantitative and qualitative methods. Quantitative information mainly includes statistical data (on socio-economic situation of local areas and households, schooling and other data of the education system) collected from annual statistical year-book and household survey. Qualitative information consists of ideas and data collected from in-depth interview and focused group discussion with represetatives of households and specialists.

Along with statistical data at the national level and some rural areas, the research team conducted sample selection in five provinces, including Vinh Phuc, Thai Binh, Quang Ngai, Ho Chi Minh (HCM) city, and Can Tho. One district was selected in each province, two communes, and three schools were chosen in each district. In total, 450 parents and 450 students were surveyed by questionnaires. Fourty-five Bureau of Education and Training (BoET) in district level specialists, 75 Department of Education and Training (DoET) in province level managers, 105 parents, 105 students, 45 school managers, and 105 commune leaders involved in interview and discussion.

\section{Research Subjects}

The research focuses on girls. According to the United Nations (UN) convention on children's rights, "Children are persons less than 18 years old, unless national law regulates earlier age of majority." In Vietnam, law on protection, care, and education of children stipulates that the youths are Vietnamese citizens less than 16 years old. Therefore, girls involved in this research are those at age of 7-15 years old. However, the concept of children regulated in law and statistical data of surveys remain inconsistent so in this research, analysis of "children" mainly refers the group of children at age of 5-17 years old (instead of 5-15 years old).

Some research results are extracted from survey, desktop review results, and in-depth discussion about schooling of girls and impacts of households' economic strategy on educational life of girls.

\section{Some Typical Features of Girls}

\section{Young Population at Age of 5-17 Years Old}

According to the survey, it is estimated that the number of Vietnamese people in 2012 was $88,687,810$ on average, including nearly $49.5 \%$ of men and more than $50.5 \%$ of women. The number of youth at age of 5-17 years old is estimated to be $18,349,629$, accounting for $20.7 \%$ of national population, including $52.2 \%$ of boys and $47.8 \%$ of girls. The ratio of young population at age of 5-17 years old in total urban and rural population is $18.4 \%$ and $21.8 \%$, respectively.

Among total population at age of 5-17 years old, $52.8 \%$ of youth at age of 5-11 years old, $22.5 \%$ at age of 12-14 years old, and $24.7 \%$ at age of $15-17$ years old.

Compared with the result of Vietnam population and housing census in 2009, until 2012, ratio of young population at age of 5-17 years old in total population tended to decrease, of which, decrease trend of girls is faster than that of boys (in 2009, ratio of children at age of 5-17 years old accounted for $22.4 \%$ of total population, including $48.6 \%$ of girls).

\section{Situation of Girls' Schooling}

For the last two decades, Vietnam has gained remarkable achievements in ensuring children to attend 
school through the adjustment and application of a series of education policies and programs to support disadvantaged children.

Based on the survey, it was estimated that in $2012,90.5 \%$ of children at age of 5-17 years old attending kindergartens, schools at different education level, and vocational schools. Ratio of 5 years old children attending preschool institutions was $93.4 \%$. The ratio of children at age of 6-17 years old attending schools at different basic education level was $90.3 \%$ (United Nations International Children's Emergency Fund [UNICEF] \& Ministry of Education and Training [MOET], 2013).

Referred from research results of UNICEF on status of children and women in 2012, and data of the survey on Vietnamese people's living standards in 2013, the ratio of schooling girls was higher than that of boys at different basic education levels nationwide, geographic areas, and age groups.

Table 1

Schooling Situation of Girls

\begin{tabular}{llcc}
\hline & Kindergarten (\%) & Primary level (\%) & Secondary level (\%) \\
\hline General & 93.4 & 97.7 & 83.9 \\
Rural area & 92.1 & 97.6 & 81.5 \\
\hline Region & & & 92.3 \\
\hline Red River Delta & 97.5 & 100.0 & 78.7 \\
Midland and northern mountain & 98.5 & 96.1 & 88.0 \\
North central and central coast & 95.8 & 98.0 & 74.8 \\
Central highlands & 94.7 & 96.2 & 82.0 \\
South East & 89.0 & 96.9 & 79.0 \\
Mekong River Delta & 81.9 & 96.1 & 47.6 \\
\hline Degree of mother & & & 76.9 \\
No degree & 79.5 & 87.7 & 90.8 \\
Primary level & 87.1 & 97.1 & 96.3 \\
Lower secondary level & 95.5 & 99.5 & 98.5 \\
Upper secondary level & 98.2 & 100.0 & \\
At least college and vocational school & 99.0 & 98.7 & 66.0 \\
\hline Living standard & & & 81.7 \\
Poorest & 92.4 & 94.9 & 89.0 \\
Poor & 88.8 & 97.9 & 96.4 \\
Average & 90.3 & 98.6 & 99.4 \\
Rich & 94.6 & 98.8 & \\
\hline Richest & 97.9 & & \\
\hline
\end{tabular}

Table 1 above shows the percentage of girls going to school is lower than this rate at the national level, at the higher education levels, the proportion of girls attending school at the right age increasingly decline. By geographic region, although the proportion of children aged 6-11 years old attending school in the areas is high, but the gap in the status of children attending school among regions remains. Accordingly, the Red River Delta has the highest ratio of children going to school, with over $96 \%$, the central highlands and South East regions have the lowest ratio of children attending school, accounting for $87 \%$ in each region. The percentage of school-aged girls also differs according to the mother's education qualification, and living standards of the family: The higher educational qualification a mother gained, the higher proportion of girls attending school at the right age. Simultaneously, the higher living standards that a family has, the greater percentage of children 
going to school. At the higher educational levels, the effects of regional factors (level of development of the region), the standard of living of the family, and the mother's education qualification have increasingly had strong impact on the proportion of school-aged girls going to school.

Among five provinces where the research team conducted the survey, according to statistical data of BoETs, the ratio of school-aged girls attending school in HCM ad Can Tho cities - two cities with high living standrds - are highest. Such ratio in Thai Binh, Vinh Phuc, and Quang Ngai-provinces with lower living standards accounts for second highest.

Based on the research team's observation, the higher number of school-aged household members, the lower ratio of school-aged girls attending school, this rate decreases significantly when girls move to the next education level.

\section{Economic Strategy of Rural Households and Its Impacts on Educational Life of Girls}

\section{Reduction in Education Cost Under Pressure on Households' Economics}

Statistical data and research results show people's spending on education has increased for the last years. This means people have to pay much for education services that they benefit from. It should be highlighted that when cost of households for their children's learning in Vietnam is mentioned, such cost includes not only tuition fee but also other receipt amounts that must be paid by parents (contribution for school development, amount for increase in the number of learning periods...) and costs outside school (learning tools/aids, text-books, and extra learning fee...). Such aspect is put in the rural area where income level is lower than average level and most of poor households are living, which reflects rural people have faced more disadvantage in payment for educational cost.

Table 2

Spending for Education, and Training for One Schooling Person on Average Within 12 Months of Rural Households

\begin{tabular}{lc}
\hline Year & Expenditure (VND) \\
\hline 2002 & $433,000.00$ \\
2004 & $602,000.00$ \\
2006 & $894,000.00$ \\
2008 & $1,354,000.00$ \\
2010 & $2,063,000.00$ \\
2012 & $3,090,000.00$ \\
Gap between 2012/2002 (times) & 7.14 \\
\hline
\end{tabular}

Source: General Statistic Office (GSO) (2012). Appendix of results of survey on household's living standards.

Survey results of a study conducted in 2007 revealed that $56 \%$ of parents in the survey sample said that expenditures for the education of their children was "Serious," $38 \%$ of them mentioned "Relatively serious," and $18 \%$ of parents said to be "Too serious" (Tran, 2008) (see Table 2). The survey data of the study titled "Current rural households' education in the context of socio-economic transformation in Vietnam" (Tran, 2016), which was done in 2014 showed that difficulties in funding children to go to school: Among 371 parents responding, $59.8 \%$ of them admitted encountering fund difficulties when their children go to school and $40.2 \%$ did not meet such difficulty. Quang Ngai is an area where parents face most difficulty in funding their children to school ( $89.0 \%$ of respondents) than the remaining provinces (39.8\% to $65.4 \%)$. 
Reason for facing difficulties in funding their children to school are given, including: (a) family's economic difficulties: given by $70.2 \%$ of respondents; (b) the high cost of schooling: given by $21.3 \%$ respondents; (c) large families (with many children): raised by $6.4 \%$ respondents; and (d) families having people of illness and disease: raised by $2.1 \%$ respondents.

Also, in this study, the comparison of the level of difficulty in arranging cost for children's learning is also mentioned. In total number of 387 surveyed people, $54.5 \%$ of parents said the arrangement of cost for their children beome more difficult than before, $25.6 \%$ identified such cost arrangement is unchanged, and 19.9\% said the cost arrangement for their children is easier than before (see Table 3). Quang Ngai is still the local area where has the highest ratio of parents thinking that the cost for learning is difficult than before $(74.3 \%$ of people of the province giving the answer) compared to the other remaining areas (ranged from $40.3 \%$ to $59.7 \%)$.

Table 3

Families Face Difficulties in Financing Their Children to School

\begin{tabular}{|c|c|c|c|c|c|}
\hline & & & \multicolumn{2}{|c|}{ Disadvantaged family } & \multirow{2}{*}{ Total } \\
\hline & & & Yes & No & \\
\hline \multirow{10}{*}{ Province } & \multirow{2}{*}{ Can Tho } & Number of respondents & 39 & 27 & 66 \\
\hline & & $\%$ in province & 59.1 & 40.9 & 100.0 \\
\hline & \multirow{2}{*}{ Quang Ngai } & Number of respondents & 65 & 8 & 73 \\
\hline & & $\%$ in province & 89.0 & 11.0 & 100.0 \\
\hline & \multirow{2}{*}{ Thai Binh } & Number of respondents & 33 & 50 & 83 \\
\hline & & $\%$ in province & 39.8 & 60.2 & 100.0 \\
\hline & \multirow{2}{*}{ HCM city } & Number of respondents & 34 & 37 & 71 \\
\hline & & $\%$ in province & 47.9 & 52.1 & 100.0 \\
\hline & \multirow{2}{*}{ Vinh Phuc } & Number of respondents & 51 & 27 & 78 \\
\hline & & $\%$ in province & 65.4 & 34.0 & 100.0 \\
\hline \multirow{2}{*}{ Total } & & Number of respondents & 222 & 149 & 371 \\
\hline & & $\%$ in province & 59.8 & 40.2 & 100.0 \\
\hline
\end{tabular}

Two hundred and eleven people who admitted facing with difficulty in cost arrangement for their children explained such reasons as: (a) increased contributions (64\% of respondents); (b) more difficulty because of extra learning (50.2\% of respondents); (c) the decrease in income ( $42.7 \%$ of respondents); and (d) increase in the number of children attending school (38.4\% of respondents).

Every year, the school requires uniforms for students. In 2013, the school required sewing of trousers, blazers, and slim coats. Unfortunately, this year, it recommends long sleeves and skirts, two-layer coats, and sneakers. Revenue is so high, my family wants to spend such amount of money for other children or other provisions. (Quoted interview of parents in HCM city, 2014)

In addition to tuition, there are many other contributions, outings, tours, why do not let my children go, and English learning, extra learning? ... A lot of money, but compared to city residents, it is not much .... At home, the children also have to do many things after school hours, they work in the fruit gardens, not too much but they like ... The children find work in the industrial parks, now there is no land for farming, after they complete Grades 9 and 10, they can go to work... (Quoted interview of parents in Can Tho, 2014)

I just want to let my child access higher education level, but he does not want to learn, he said if he wanted to attend college, he had to learn in the city, but in the city, apart from learning cost, he had to pay for accommodation, meals... How can he earn such amount of money? ... (Quoted interview of parents in Vinh Phuc, 2014) (Source: Tran, 2016) 
Sixty-four percentage of the surveyed people said that the cost arrangement for their children's learning was more difficult than before due to increased contributions and extra learning (the increased cost of learning), which needed to be paid due attention, because the purpose of free compulsory education is to create equality of opportunity for all children in the society, irrespective of wealth.

Basic education was to create equality of opportunity for all children, but currently, the education system in Vietnam increasingly declines educational opportunities for children from poor families. The group of richest families with highest expenditure (Group 5 in classification of five levels) spends nearly 11 times higher expenditure on education than the poorest group (Group 1). The survey results confirm an alarming situation as follows: The poorer households, the higher proportion of education spending on the total expenditure for the life, although the amount of expenditure on education of such households is much lower than that of richer ones. This means that for the poorer households, the heavier burden of expenditure on education for their children for the family budget. Many poor families are therefore more likely to let their children leave school early, if their children do not learn well, this possibility is even more likely to occur.

But, at the same time, though such poor families want their children to learn at the higher level, the majority of them can not afford their children to attend higher grades, especially from junior high school to high school level. And more children from more affluent families have more opportunities to learn at high school level than the children of needy families. With the rate of $73 \%$ of poor households located in rural areas, it is clear that rural households face unfavorable conditions of accessing education services.

Table 4 below shows the percentage of expenditure on education in total annual expenditure of rural households. The figures in Table 4 show the percentage of expenditure on education of the households decreases every year. The poorer households are, the quicker declining speed of the percentage of expenditure on education in total household's spending over the years. In correlation with the increasing contribution of households in total expenditure on education (as mentioned above), it is clear that the poor are increasingly difficult in the use of educational services.

Table 4

Evaluation of Parents on Changes in Arrangement of Learning Costs for Their Children

\begin{tabular}{|c|c|c|c|c|c|c|}
\hline & & & \multicolumn{3}{|c|}{ Changes compared with the past } & \multirow[b]{2}{*}{ Total } \\
\hline & & & $\begin{array}{l}\text { Easier } \\
\text { than before }\end{array}$ & Unchanged & $\begin{array}{l}\text { More difficult } \\
\text { than before }\end{array}$ & \\
\hline \multirow{10}{*}{ Province } & \multirow{2}{*}{ Can Tho } & Number of respondents & 14 & 24 & 36 & 74 \\
\hline & & $\%$ in province & 18.9 & 32.4 & 48.6 & 100.0 \\
\hline & \multirow{2}{*}{ Quang Ngai } & Number of respondents & 7 & 12 & 55 & 74 \\
\hline & & $\%$ in province & 9.5 & 16.2 & 74.3 & 100.0 \\
\hline & \multirow{2}{*}{ Thai Binh } & Number of respondents & 21 & 21 & 43 & 85 \\
\hline & & $\%$ in province & 24.7 & 24.7 & 50.6 & 100.0 \\
\hline & \multirow{2}{*}{ HCM city } & Number of respondents & 15 & 31 & 31 & 77 \\
\hline & & $\%$ in province & 19.0 & 40.3 & 40.3 & 100.0 \\
\hline & \multirow{2}{*}{ Vinh Phuc } & Number of respondents & 20 & 11 & 46 & 77 \\
\hline & & $\%$ in province & 26.0 & 14.3 & 59.7 & 100.0 \\
\hline \multirow{2}{*}{ Total } & & Number of respondents & 77 & 99 & 211 & 387 \\
\hline & & $\%$ in province & 19.9 & 25.6 & 54.5 & 100.0 \\
\hline
\end{tabular}

The first solution of rural households to overcome pressure of educational cost is reducing costs, which is shown through decrease in the number of schooling children and reduction in costs outside tution fee. This 
solution has strong and direct impact on educational life of girls.

Decrease in the number of members involved in education. As above-mentioned, the number of rural girls going to school is lower than the national rate, which means some school-aged girls have to drop out. The rate of schooling girls decreases grade after grade. Statistical data on dropu-out students show this rate tends to increase, of which, the rate of drop-out girls is higher than that of drop-out boys.

According to the survey results at five provinces, $95.8 \%$ of questioned parents said that they did their best to afford their children's learning and had no discrimination between girls and boys. However, in reality, $11.3 \%$ of surveyed households have school-aged family members (6-15 years old) who stopped going to school, of which, $56.9 \%$ of drop-out students being girls, and $22.5 \%$ of households having school-aged members who stopped attending class for a long time (more than 45 days), including $73.6 \%$ of girls (see Table 5).

Table 5

Rate of Educational Expenditure in Total Annual Expenditure of Households

\begin{tabular}{llll}
\hline Income group & $2008(\%)$ & $2010(\%)$ & $2012(\%)$ \\
\hline Group 1 (Poor) & 6.5 & 4.5 & 2.9 \\
Group 2 (Nearly poor) & 7.6 & 6.4 & 4.2 \\
Group 3 (Average) & 6.8 & 6.4 & 4.4 \\
Group 4 (Affluent) & 7.4 & 6.1 & 4.5 \\
Group 5 (Rich) & 6.7 & 5.7 & 3.5 \\
\hline
\end{tabular}

Source: GSO (2012). Appendix of survey results of household's living standards.

Reduction in the number of extra classes and extracurricular activities. Economic pressures forces parents to cut costs for the education of children, such as participation in extra learning or extracurricular activities. Most parents participating in seminars and interviews agreed that the first priority criterion is their children's learning ability - who learns well will not attend extra learning anymore, who learn weakly will attend class to get support from teachers. However, further discussions showed that if the learning ability of the two children is similar, the girls always behind, always be forced to prune their learning needs for her brothers. Girls take over, it is good if girls are fond of self-learning, but boys are playful, so they need to attend class to get teachers' support or girls work harder, and more industriously, if they do not understand, they will ask their friends, but boys only play when they learn in group. Although they do not intentionally discriminate girls it is clear that the perception of the characteristics of girls and boys of the parents makes girls face disadvantages when parents are forced to cut spending on the children's learning.

My parents do not have money for extra-class, so I do not attend any tutorial class. I still understand lessons but my marks are not as high as that of my friends... (Extracted interview with a girl in Thai Binh province, 2014)

I do not learn English because my parents cannot afford, and they have to save money for my siblings' learning... (Extracted interview with a girl in Can Tho province, 2014)

My brother can ask money for playing electronic games, but I cannot ask money for extra-class learning... (Extracted interview with a girl in Vinh Phuc province, 2014) (Source: Tran, 2016)

At a stable economic situation, $85.3 \%$ of parents think that there is no discrimination between boys and girls in extra-class but $14.7 \%$ of parents think there is discrimination. Not attending extra-class makes girls face more disadvantages of achieving better learning results at school and more risk of feeling bored with learning or dropping out, or they cannot attend class at higher grades. 


\section{Priority Choice in Education Investment}

The results of data analysis from household survey also show correlation between the settlement of the financial difficulties of the family (bank loans, borrowing from friends, sale of house, sale of assets, and utensils) to send their children to school with selection of higher level. Accordingly, the correlation between settlement plans to let boys attend higher level is much tighter than this correlation for girls. Parents are willing to get bank loans, borrow from family and friends, or sell assets and utensils to afford boys to attend higher level, especially college and university, but such readiness for girls dropped much.

\section{Delay in Paying Tuition Fee and Reduction in Auxiliary Payment}

Delay in paying tuition fee is one of temporary solutions of households in the context of difficult economic situation. Seventeen point nine percentage of asked households said "did not pay tuition fee as scheduled," of which, Can Tho had the highest rate of families paying tuition fee late (22.5\%) and Vinh Phuc had the lowest rate $(9.8 \%)$. The reasons for families paying tuition fee late was mainly due to the fact that "my parents did not have money (72.85\%)," $22.52 \%$ of students said they forgot to ask for money from their parents, and $6.62 \%$ of students said "my parents gave me money but I spent money on other things."

It is noted that delay in tuition fee payment has remarkable impacts on students' tireness of learning. Seventy-eight point five percentage of girls felt ashamed when they paid tutition fee late. This also explains the fact that the higher grade the students attend, the lower rate of late tuition fee payment, because when students learn at higher grades, they are more aware of timely tuition fee payment and feel shameful of late tutition fee payment with friends and teachers. Eighty-five point six percentage of girls felt ashamed of late tuition payment while this rate of boys is $55.2 \%$.

Among the reasons for tireness of learning from surveyed students, many reasons are related to economic aspect of the family, such as delay in fee payment, no money to buy uniforms, or hire clothes for extracurricular activities, not enough money for boarding accommodation. These details make girls feel ashamed and be absent from school (short-term, long-term period, or even drop-out). While boys feel bored of learning mainly because of such reasons as fond of playing games, or they do not understand teachers' lecture.

Based on survey results, the research team analyzed the relation between sex and times of absence from class and drop-out, then analyzed this relation with intervention of information about reason for absence from class. Analytical results show that for absence for short-term period (less than five days/school-year), the number of absent girls is lower than that of absent boys but for long-term period (at least 10 days/school-year, even some students were absent for 35 days/school-year), the number of absent girls is higher than that of boys. The reasons include family aspects $(73.5 \%)$, illness (15.5\%), and other reasons. "Family reason" was specified by students in the discussions, such as parents did not have money, they did not have rice to take to school, they did not take part in extra-curricular activities, and they did not have uniform.

\section{Mobilization of Girls' Involvement in households' Economic Strategy}

Studies show that children in rural households, especially girls play an important role in the economic development strategy of households through direct participation on income generation or support for members to earn income.

Do housework for adults to go to work. According to national survey on child labor in 2012, non-schooling children spent time on many different activities, such as working, helping with household tasks, 
recreation, and other activities. It was found that, in general, 70\% of time spent by non-schooling children to work or support their families and only $30 \%$ of time used for recreational, entertainment, and other activities. Of course, there are differences among age groups, 5-11 years old children use less time for working; 12-14 years old children use $71 \%$ of time to work and support their families while this proportion of 15-17 years old children was $75 \%$. The older age is, the more work is and less resting and playing. Girls also have to work more and spend less time on entertainment and other activities than boys. No differences in the trend of spending time of children not attending school between urban area and rural area.

Results of interview and discussion with parents in the provinces where the research team conducted the survey also give similar findings.

After school hours, my child helps us like a baby sitter, feeding pigs and chickens, and fining vegetables, cooking ... (Quoted interview of parents in Vinh Phuc province, 2014)

My daughter has grown up, after she finishes learning, she helps her mother bear buttons, gaining 400 VND shirt and 250 VND pants. (Quoted interview of parents in Thai Binh province, 2014)

Girls are assisting the mothers with housework, the sons are playful, playing games boys need to grow up more to work with fathers. (Quoted interview of parents in Can Tho, 2014) (Source: Tran, 2016)

According to estimates from the National Survey of Child Labour in 2012, 9,956 children aged 5-17 years old (accounting for over 50\% of the population in this age group) participated in doing housework. Among housework, children are most involved in the clean-up, cleaning house, cooking for the family, washing clothes, acting like baby sitter, and caring for the sick.

Most children do housework for 5-20 hours/week (63.8\%). However, 30.7\% also does housework less than five hours/week. Especially, $4.6 \%$ of children doing housework for $20-40$ hours/week and $1.7 \%$ of children doing housework for over 40 hours/week

Children in rural areas participate in doing more housework than urban children; girls participate more in doing housework than boys; and children at older age groups participate in doing housework than children at smaller age group.

The research team surveyed the households by questionnaire on time of doing housework by children aged 6-15 years old. Result analysis of the data shows that among 336 people giving answers in total, $87.5 \%$ answered their children helping with housework and $12.5 \%$ answered their children did not help with housework. Vinh Phuc is a local area where the number of children helping parents with housework accounts for the highest ratio compared with remaining localities.

Housework doing time of children is presented in the Table 6 and Figure 1 as below:

Table 6

Housework Time of Children

\begin{tabular}{lllllll}
\hline \multirow{2}{*}{ Children } & \multicolumn{3}{c}{ Sex } & \multicolumn{3}{c}{ Time (hours/day) } \\
\cline { 2 - 3 } \cline { 5 - 6 } & Boys (\%) & Girls (\%) & & $1-4 \mathrm{~h}(\%)$ & $5-8 \mathrm{~h}(\%)$ & $>8 \mathrm{~h}(\%)$ \\
\hline The first child & 32.2 & 67.8 & 92.5 & 6.2 & 1.2 \\
The second child & 31.3 & 68.7 & 95.8 & 3.2 & 1.1 \\
The third child & 36.9 & 63.1 & 93.1 & 3.4 & 3.4 \\
The forth child & 50.0 & 50.0 & 100.0 & - & - \\
The fidth child & 50.0 & 50.0 & 100.0 & - & - \\
\hline
\end{tabular}

Source: MOLISA, GSO, \& International Labor Organization (2014). 
Overall, the daughter much more engaged to help parents do the housework more than boys in the family, daughters spend much time assisting housework. Among the parents responded, 90\% had children help the family with time from one-four hours/day, of which over $40 \%$ help parents about one hour/day, over $30 \%$ help parents around two hours/day, and 10\% help parents around three hours/day.

Results of the national survey on child labor, and for a similar result, over $50 \%$ of children participate in household chores to help parents, including children and women participating in work home than boys (Dang \& Halsey, 2013).

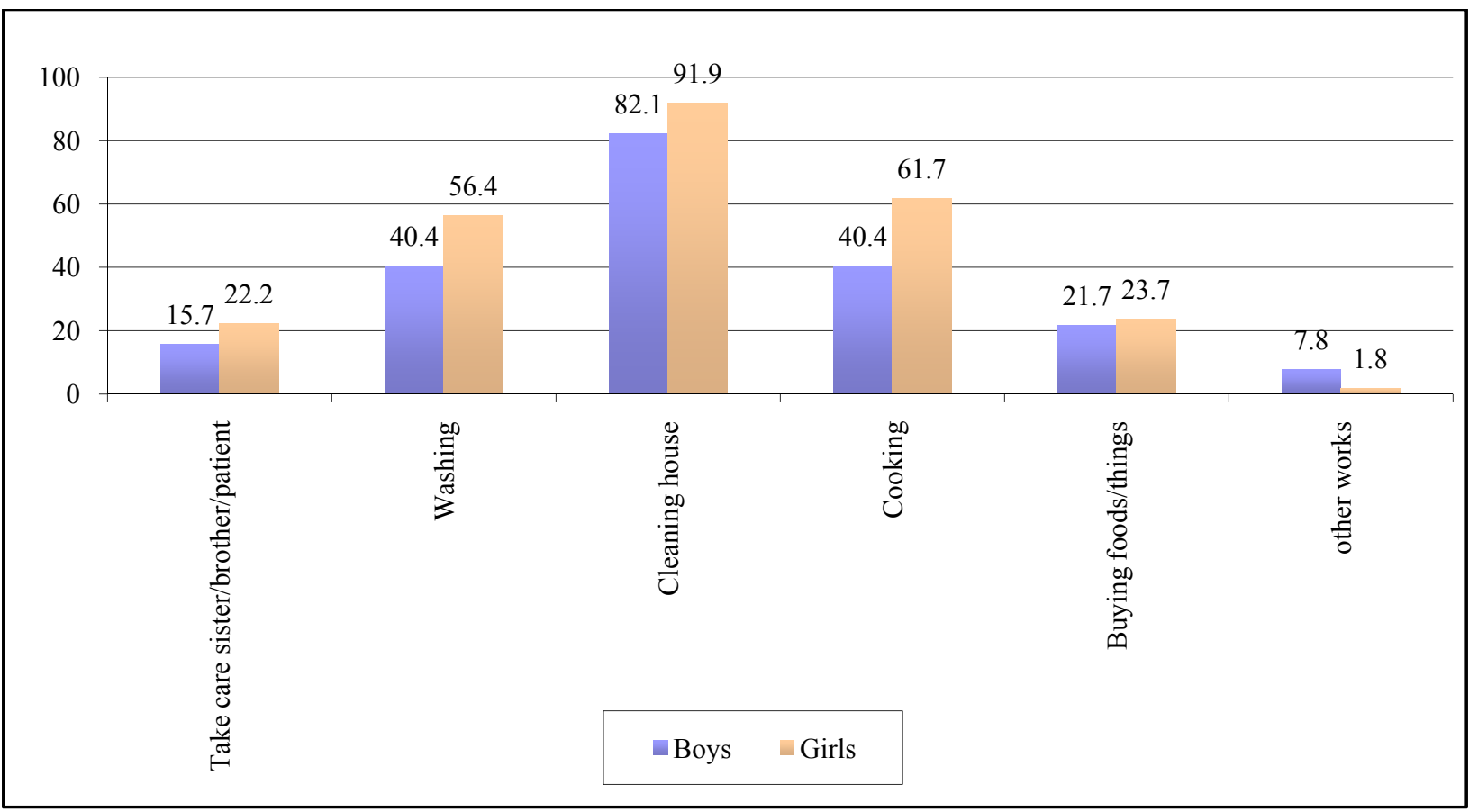

Figure 1. Housework doing time of children in the families.

Participation in income generation activities. When asked about the child labor with family income generation: $81.8 \%$ of the answers given children in school age labor not generate income for the family, but still have $18.2 \%$ of the answers children school age labor to family income. The percentage of families with children in school-age workers have the highest income in Vinh Phuc and Quang Ngai, who in turn is $23.4 \%$ and $23.2 \%$ of people give the answer of the province.

Labor time for income generation of children is presented in the Table 7 below:

Table 7

Labor Time for Income Generation of Children

\begin{tabular}{|c|c|c|c|c|c|}
\hline \multirow{2}{*}{ Children } & \multicolumn{2}{|c|}{ Sex } & \multicolumn{3}{|c|}{ Time (hours/day) } \\
\hline & Boys (\%) & Girls (\%) & $1-4 \mathrm{~h}(\%)$ & $5-8 \mathrm{~h}(\%)$ & $>8 \mathrm{~h}(\%)$ \\
\hline The first child & 34.5 & 65.5 & 78.6 & 14.3 & 7.1 \\
\hline The second child & 21.7 & 78.3 & 91.7 & 8.3 & - \\
\hline The third child & 22.9 & 77.1 & 83.3 & 16.7 & - \\
\hline The forth child & - & 100.0 & 100.0 & - & - \\
\hline
\end{tabular}

Source: MOLISA, GSO, \& International Labor Organization (2014). 
Female labor participating in family income earning is still higher than the boys. However, it seems the older boys when they join the labor activities generate more income for families at a young age.

Results of the national survey on children shows that in total 18.3 million children 5-17 years old, about 2.83 million children participate in economic activity, accounting for nearly $15.5 \%$ of the population groups this age. Participation rate of economic activity of this age group in urban areas was $7.56 \%$; and rural areas is $18.62 \%$. The proportion of rural areas is 2.5 times higher than in urban areas.

Rural children engaged in economic activities not only represent a high proportion of rural children (18.6\%), but also a large proportion of children engaged in economic activities of the country. In total, 2.83 million economically active children, there were more than 2.43 million children from rural areas, accounting for $85.8 \%$ of the total number of children engaged in economic activities of the country. This condition can be caused by household income in rural areas is lower than in urban areas, children must participate in economic activities to help to raise household income. Furthermore, rural economy mainly economic forms of household, agricultural sector, and small industry and sector is a form that children easily engaged.

In urban areas, there are about 400,000 children participated in economic activity, accounting for about $14.1 \%$ of the total group of children 5-17 years old. It was found that the level of participation of economic activity of children in urban areas is much lower than in rural areas (children 5-17 years old in urban areas accounted for $28.8 \%$ of all children at this age group of the country).

Table 8

Scale and Distribution of Rural Children Involved in Economic Acivity

\begin{tabular}{lllll}
\hline \multirow{2}{*}{ Sex } & Ratio (\%) & \multicolumn{3}{c}{ Age group } \\
\cline { 3 - 5 } & & $5-11(\%)$ & $12-14(\%)$ & $15-17(\%)$ \\
\hline General & 100.0 & 12.9 & 31.1 & 55.9 \\
Boys & 58.2 & 12.7 & 30.2 & 57.1 \\
Girls & 41.8 & 13.3 & 32.4 & 54.3 \\
\hline
\end{tabular}

Source: MOLISA, GSO, \& International Labor Organization (2014).

We need to consider the attendance of children engaged in economic activities as it indicates the involvement of economic activity that affect the child's learning. If children combine learning and working in appropriate time, we can consider working is voluntary or for family support, whereas if children leave school to work, which means that forced working required to meet the economic needs of the children themselves and families.

Estimates from the survey (see Table 8) showed that there are about 1,625,000 children, equivalent to $56.4 \%$ of children are engaged in economic activity is still under study-This means that, for this group of children, involvement in economic activity is acceptable, which does not affect school attendance. However, because 1,204,000 (or 43.6\%) students of this age group are economically active and not attending school, so enrollment rate of the children in the group of participating in economic activity was significantly lower than the average rate of attendance of the total number of children in the country (56.4\% vs. $90.5 \%)$.

Of the more than 2.83 million students have participated in economic activity, there are about 1.18 million $(41.6 \%)$ children were out of school and approximately $567,000(2 \%)$ children never go to school. This percentage is higher than the $1.35 \%$ of the population of children never goes to school an average of the country. 
Table 9 below shows that girls seem to tend recently joined economic activity has continued to study more than boys with a $60.1 \%$ rate still in school while this rate in children son just $53.6 \%$. Boys participate in more economic activity, which explains the ratio of girls to go to school at all levels of education is higher than the proportion of boys. One thing to note is that although girls engage economic activity but durations less work (number of hours worked per week) back for more.

Table 9

Schooling Status of Children Involved in Economic Activity

\begin{tabular}{llll}
\hline Sex & \multicolumn{3}{c}{ Schooling status } \\
\cline { 2 - 4 } & Learning (\%) & Learnt (\%) & Never go to school (\%) \\
\hline General & 56.4 & 41.6 & 2.0 \\
Boys & 53.6 & 44.3 & 2.0 \\
Girls & 60.1 & 37.9 & 2.0 \\
\hline
\end{tabular}

Table 10

Duration of Participating in Economic Activities of Rural Children

\begin{tabular}{lccc}
\hline Number of weekly working hours & General (\%) & Boys (\%) & Girls (\%) \\
\hline$\leq 5$ & 9.9 & 9.0 & 11.2 \\
$6-24$ & 49.0 & 47.5 & 51.0 \\
$25-42$ & 22.7 & 21.3 & 23.7 \\
$>42$ & 18.1 & 16.2 & 19.5 \\
Not identified & 0.3 & 0.3 & 0.4 \\
\hline
\end{tabular}

Source: MOLISA, GSO, \& International Labor Organization (2014).

Involvement in economic activity (directly generate income or indirectly support parents) has strong impacts on educational life of girls through the following aspects:

1. Less time spent on studying at home: With the amount of time and work items that girls undertake in time not to go to school, girls have less time devoted to studying at home and significantly affect academic performance in school. "You look that I did not have time to study and to complete class assignments not make me ashamed," "I usually just cooking just studying," "Let the pig and chicken supper new study," ... is the statements of the exchange students studying at home on time. Clearly, there is little time for studying and homework preparation significantly affects the quality of learning of girls. The higher grades girls attend in, the higher number of lessons they have to do but girls have to spend more time doing housework, which makes them face more disadvantages in achieving high learning results.

2. Early participation in economic activity: It makes girls neglect learning, leading to decease in their learning outcomes, motivation for learning at higher level is also affected very much. As presented in Table 10, there is a correlation between maternal educational level and proportion of children attending school involved in economic activities. The percentage of children attending school involved in the greater economic activity among mothers with lower education levels. The results of interviews and group discussion for an explanation by Institute for Computational Design (ICD) Research focus: The parents of children of primary or early secondary schools now often move in about 15-20 years ago. The research on the reasons for the dropout of students 15-20 years ago showed that the main reason why children drop out of school because of economic reasons was the starting point for the collection of fees rather than government subsidies. The mother herself stopped learning was to engage economic activity, or in other words, economic reasons led to less educated 
mothers. One consequence is accompanied by low education, a mother can only make a living by unskilled labor which children easily join together, leading to girls in families with mothers with low education levels often learning by doing more to help mothers increase their income. The survey on labor careers that girls involved had better illustration for this assertion. Accordingly, most of the jobs that workers participating girls were outsourcing things like costumes, retail and mobile services market, service for drinks, food retailers, tobacco, alcohol, or crop and livestock production.

3. Early marriage: Early marriage is the next step when girls stop going to school. In the current context of economic transformation of rural areas, the number of purely agricultural households is declining. Instead, the number of communes and households with mixed trades is increasing. Most households are seeking to increase their income by selling or doing professional tasks, employment besides rice paddy. The scale of economic activity is often small and attracts family laborers, namely, children. The stronger income generating activities of households, the greater participation of children and this attractive force pulls children out of school strongly—-boys are involved in labor directly, girls get married early to increase labor.

\section{Conclusions}

The study titled "Households' education in rural area in the current context of socio-economic transformation in Vietnam" was implemented in five provinces representing five regions of Vietnam. One of results of this study is impact of rural households' economic strategy on educational life of girls. Although this study orientation was not identified in the beginning, it is an important finding of the research team during the implementation period (Tran, 2016). This study result also coincides with survey results of other studies on women and children, which makes the research team feel confident when analyzing results:

1. Rural households are really difficult in paying educational costs, the higher grades students attend, the higher pressure of educational cost payment.

2. Rural households have made great efforts to afford their children to learn at the highest grade, but they still have to cut costs temporarily (late payment of tution fee, not buying uniform, delayed purchase of learning aids...) or for long-term period (no extra-class, not learning subsidiary subjects, and not joining extra-curricular activities), some educational costs .... Although no discrimination between girls and boys is confirmed, girls always have to give up what is their due to their younger/elder brothers and this reduction influences more on girls than boys.

3. Households mobilize children in economic development activities with more participation of girls, which has impacts on children's learning at different levels: (a) learning ability decreases due to lack of time for lesson review; (b) temporary drop-out, absence from class for short-term period; and (c) absolute drop-out. Although the rate of drop-out children for participating in economic activity is small, the number of children at age of 5-17 years old is high. Therefore, every year witnesses the fact that millions of school-aged children do not go to school or leave school.

\section{References}

Dang, H. A., \& Halsey, R. (2013). The decision to invest in child quality over quantity, household size, and household investment in education in Vietnam. The World Bank Economic Review Forthcoming, 1.

Ministry of Education and Training (MOET), United Nations International Children's Emergency Fund (UNICEF) \& United Nations Educational, Scientific, and Cultural Organization (UNESCO). (2008). Report on "Transition from primary level to lower secondary level of ethnic minority girls”. Ha Noi: Vietnam. 
Ministry of Labour, Invalids and Social Affairs (MOLISA), General Statistics Office (GSO), \& International Labor Organization (ILO). (2014). Naional survey on child labor-Key findings. Ha Noi: Vietnam.

Tran, H. Q. (2008). From family to teachers: Socio-economic issues in basic education, report on results of survey in November and December, 2007 in five Southern provinces, HCM city. Vietnamese Review of Studies and Dícusions, 13.

Tran, T. T. H. (Ed.). (2016). Current education strategy of rural households: Situations and solutions. Ha Noi: National Political Publishing House.

UNICEF, \& MOET. (2013). Report on children outside school: Research of Vietnam. Ha Noi: Vietnam. 